\title{
Radiofrequency Treatment of Facet-related Pain: Evidence and Controversies
}

\author{
Jan Van Zundert • Pascal Vanelderen • Alfons Kessels • \\ Maarten van Kleef
}

Published online: 18 November 2011

(C) The Author(s) 2011. This article is published with open access at Springerlink.com

\begin{abstract}
Pain originating from the lumbar facet joints is estimated to represent about $15 \%$ of all low back pain complaints. The diagnostic block is considered to be a valuable tool for confirming facetogenic pain. It was demonstrated that a block of the ramus medialis of the ramus dorsalis is preferred over an intra-articular injection. The outcome of the consequent radiofrequency treatment is not different in patients reporting over $80 \%$ pain relief after the diagnostic block than in those who have between $50 \%$ and $79 \%$ pain relief. There is one wellconducted comparative trial assessing the value of one or two controlled diagnostic blocks to none. The results of the seven randomized trials on the use of radiofrequency treatment of facet joint pain demonstrate that good patient selection is imperative for good clinical outcome. Therefore, we suggest one block of the ramus medialis of the ramus dorsalis before radiofrequency treatment.
\end{abstract}

Keywords Facet joints · Zygapophyseal joints · Low back pain - Diagnostic block - Medial branch block .

Radiofrequency treatment . Evidence rating . Pain management

J. Van Zundert $(\square) \cdot$ P. Vanelderen

Department of Anesthesiology and Multidisciplinary Pain Centre, Ziekenhuis Oost-Limburg,

Campus André Dumont, Stalenstraat 2,

3600 Genk, Belgium

e-mail: Jan.VanZundert@zol.be

\section{A. Kessels}

Department of Clinical Epidemiology and Medical Technology

Assessment, University Hospital Maastricht,

PO Box 5800, 6202 AZ Maastricht, The Netherlands

M. van Kleef

Department of Anesthesiology and Pain Management, University Hospital Maastricht,

PO Box 5800, 6202 AZ Maastricht, The Netherlands

\section{Introduction}

The lumbar facet joints (zygapophyseal joints) form the posterolateral articulations connecting the vertebral arch of one vertebra to the arch of the adjacent vertebra. As true synovial joints, each facet joint contains a distinct joint space capable of accommodating between 1 and $1.5 \mathrm{~mL}$ of fluid, a synovial membrane, hyaline cartilage surfaces, and a fibrous capsule [1]. The facet joint capsule and surrounding structures are innervated. Chemical or mechanical stimulation of the facet joints and their nerve supply elicit back and/or leg pain [2].

The prevalence of facet-mediated pain varies in different studies from less than $5 \%$ to as high as $90 \%$. Studies conducted in well-selected patient populations, using welldefined diagnostic criteria, indicate a prevalence around $15 \%$ [3]. Facetogenic pain is predominantly caused by repetitive stress and/or cumulative low-level trauma; the resulting osteoarthritis leads to inflammation, which can cause the facet joint to be filled with fluid and swell, which in turn results in stretching of the joint capsule and subsequent pain generation. Inflammatory changes around the facet joint also can irritate the spinal nerve via foraminal narrowing, resulting in sciatica $[4 \cdot \bullet]$. The most frequent complaint is axial low back pain. Sometimes, pain may be referred into the groin or thigh.

Lumbar paravertebral tenderness is indicative of facetogenic pain [2]. When pain gets worse by flexion and extension, it may be suggestive of pathology originating from the lowest lumbar segments.

Medical imaging, especially computed tomography (CT) scan, visualizes degenerative changes of facet joints. The degree of degeneration is not correlated with pain intensity, as demonstrated by the observation that abnormalities have been observed in asymptomatic patients $[4 \bullet \bullet]$. 
In patients with a clinical diagnosis of facet joint pain, CT- single-photon emission CT fusion imaging of the lumbar spine can indicate a "hot" lesion. In one study, injection of these lesions with local anesthetic was associated with complete resolution of pain [5]. A positive diagnostic block was judged to be a definite criterion for lumbar facet joint pain by $90 \%$ of an expert panel [6]. This technique is commonly used to find confirmation of the presumed causative level. Conservative treatment consisting of pharmacotherapy, cognitive behavioral therapy, manual medicine, exercise therapy and rehabilitation, and, if necessary, a more detailed psychological evaluation, is the first-line treatment.

The use of intra-articular corticosteroid injections in the facet joints is controversial. Uncontrolled studies have demonstrated transient beneficial effects, but the results of controlled studies have been mostly disappointing. Radiofrequency (RF) treatment of the facet joints is currently considered the standard treatment of facet-mediated persistent pain.

\section{The Evidence}

A recently published practice guideline for the interventional management of facet pain assessed the available evidence and issued a recommendation [4••]. On one hand, the recommendation consists of a numerical value (1 or 2) indicating whether the potential benefits outweigh the risk and/or burden. When the benefit due to the effectiveness of the treatment was greater than the risk and burden of potential complications, value 1 was given. Value 2 was given when the benefit of the effect was closely balanced with the risk and burden of possible side effects. On the other hand, a letter indicates the level of the evidence (A, B, or C). A indicates the highest level of evidence (various randomized controlled trials [RCTs] of good quality), B represents evidence derived from large observational studies or RCTs with methodological limitations, and $\mathrm{C}$ is assigned when the evidence is limited to observational studies or case series. Additionally, a score of " 0 " was given for techniques that are only described in case reports. Finally, the evidence was interpreted for outcome, indicated as follows: positive outcome $(+)$, negative outcome $(-)$, or, when both positive and negative studies were included, $( \pm)$ was used.

RF treatment of the ramus medialis (medial branch) of the ramus dorsalis, or facet denervation was given a score $1 \mathrm{~B}+$, which implicates a positive recommendation. Seven controlled studies support this recommendation. In the first controlled study, 41 patients with chronic low back pain were selected when an intra-articular injection of local anesthetic induced some pain relief [7]. These patients were randomized to receive either "sham" or true RF treatment of the rami mediales of the ramus dorsalis. The two study groups then were subdivided into patients who obtained "good" and "equivocal" relief after the diagnostic block. After 6 months, actively treated patients who initially experienced good relief from the test blocks had a significant different improvement compared with patients from the control group.

In a well-designed placebo-controlled study, good pain relief lasting up to 12 months after RF treatment ensued in patients who experienced at least $50 \%$ pain relief for the duration of action of the local anesthetic after a diagnostic block [8]. Another placebo-controlled trial found no difference between the active treated group and the sham group 12 weeks after the intervention [9]. This study has been criticized because the criterion for a positive "diagnostic" block was $24 \mathrm{~h}$ of pain relief after lidocaine infiltration during the week after the administration of the local anesthetic. Moreover, the effect was assessed by the family doctor. In this manner, $94 \%$ of the screened patients with back pain were selected for participation, which is much greater than the presumed prevalence for lumbar facetogenic pain (around 15\%) in this cohort. For this reason, this study is judged to have major conceptual flaws. Van Wijk et al. [10] also found no difference between the treatment and control groups with regard to visual analogue scale (VAS) pain score, medication usage, and function. However, the RF group in this study did report $50 \%$ reduction in complaints significantly more often $(62 \%$ vs $39 \%)$ than those who received a sham procedure. The evaluation method consisted of a composed outcome measure of median and maximum pain intensity, daily activities, and analgesic intake, which may be subject to discussion. In the most recent RCT, a significantly greater improvement in pain symptoms, global perception of improvement, and quality of life was observed after 6 months in patients allocated to RF treatment [11]. Patients with signs and symptoms of facetogenic pain were further screened with three diagnostic blocks, and only those who had a positive response to the three blocks were randomly assigned.

Conventional RF treatment was compared with pulsed RF treatment of facetogenic pain in two randomized trials. Both showed conventional RF to be superior $[12,13]$.

From Table 1, where the method for selecting the patients is illustrated per study, it becomes clear that a block of the ramus medialis is preferable to intra-articular injection as diagnostic block. Assessment should preferentially be done in the recovery area, where patients report the pain intensity on a VAS scale at regular time points for the duration of action of the local anesthetic. Table 2 details the relevant clinical trials. 


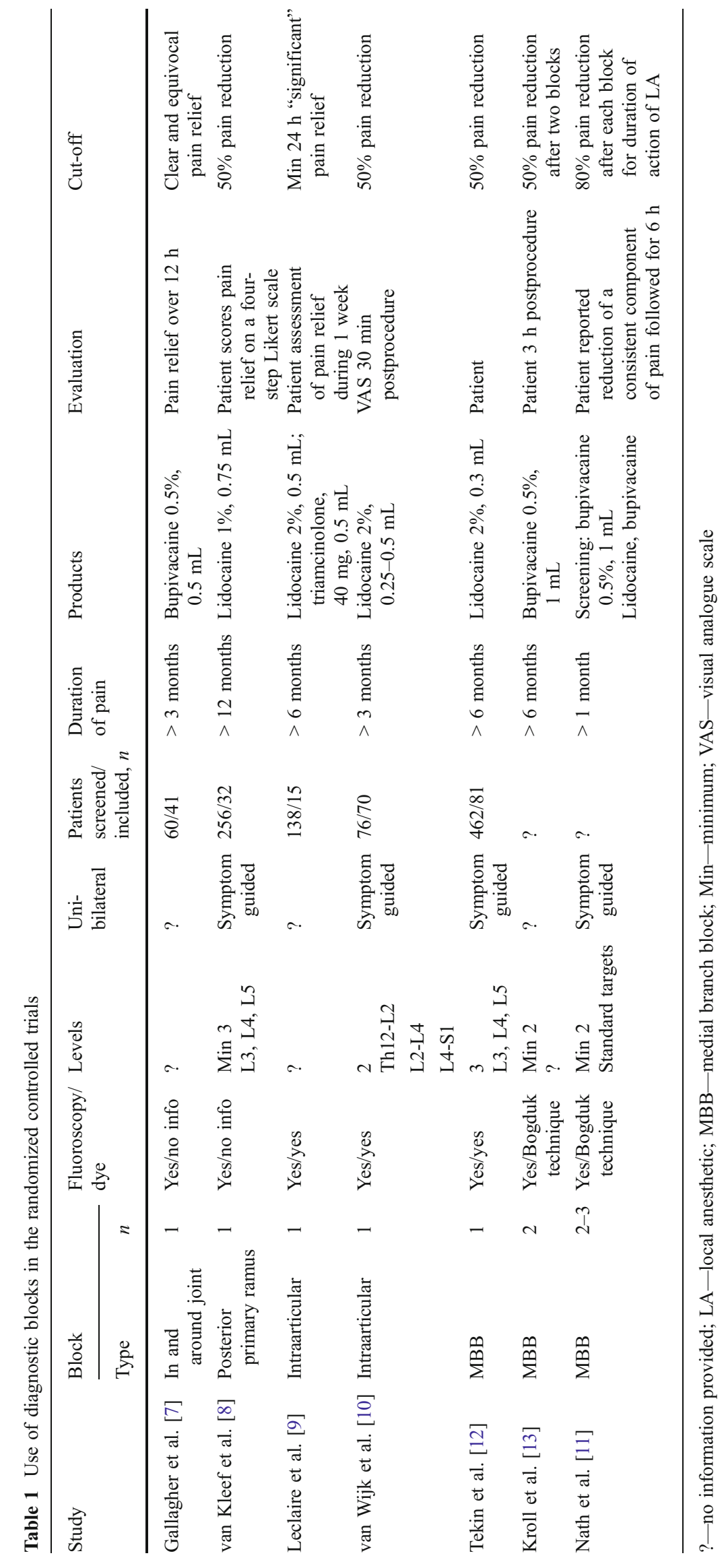




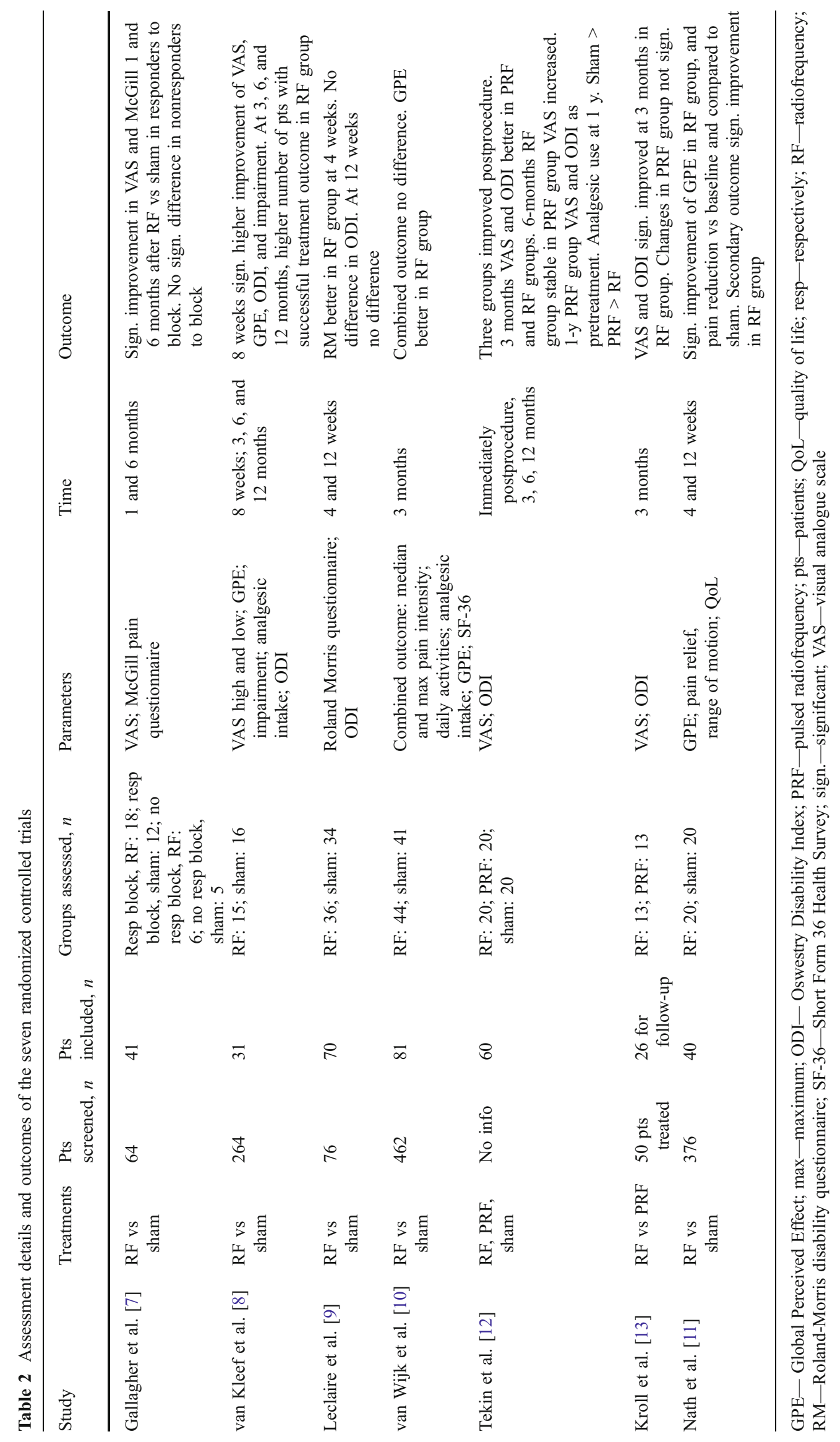




\section{Reviews}

Several groups have performed a review of the available evidence [14-21, 22•]. The outcomes of those reviews depend on the type of studies included and the opinion of the reviewers, which may result in different evidence levels. The most recent review [22•] concludes that there is insufficient (poor) evidence from randomized trials (conflicting trials, sparse and lower-quality data, or no randomized trials) to reliably evaluate a variety of interventional therapies for spine-related pain, including RF denervation. Although the title states that this is a systematic review, it looks more like a narrative review because the authors did not comply with general guidelines of writing a systematic review of RCTs, the Quality of Reporting of Meta-analyses (QUOROM) statement [23] and now the Preferred Reporting Items for Systematic Reviews and Meta-Analyses (PRISMA) statement [24]. The main problem is the lack of structured overview of the results. The authors discuss the value of the treatment based on previous reviews and do not present the outcomes of the trials in a structured way. Their conclusion was based on six trials. Several of these six trials had shortcomings. Three studies did not report the standard errors of the change in time $[7,10,12]$. One study did not do an intention-to-treat analysis [7], and in another study flaws were detected in the assessment of the diagnostic block, as described above [9].

To analyze the effect of intervention, we performed a metaanalysis including all these six trials, which showed a significantly better effect of RF compared to placebo $(95 \%$ CI, $0.6-1.5$ on a 10 -point scale; $P<0.001)$. Furthermore, if we only included the trials without shortcomings [8, 11], the analysis even showed a significantly better result for RF $(95 \%$ CI, $0.7-3.1$ on a 10-point scale; $P=0.002$ ) [25•]. The results of these two different analyses indicate that RF treatment of the facet joints is significantly more effective than placebo [25•].

\section{Retreatment}

$\mathrm{RF}$ facet denervation is a relatively simple procedure for which a low incidence of side effects is reported [26]. Therefore, this procedure can be repeated when pain recurs. A study assessing the effect of one, two, or three RF treatments of the ramus medialis of the ramus dorsalis showed that initial responders also had a positive response to the second and the third intervention. The duration of effect was about 10 months per procedure and this period did not change when the intervention was repeated [27]. In a prospective trial, five patients received a repeat intervention; the mean duration of effect of the second intervention tended to be longer than the duration of effect of the first intervention [28•].

\section{Factors Predicting Outcome}

The factors predicting outcome of RF facet denervation were assessed in a retrospective chart review. Patients with paraspinal tenderness were more likely to have significant pain reduction 6 months after the intervention. Response to facet loading, long duration of pain, and previous back surgery were factors associated with treatment failure [29]. A recently published prospective observational study found depression, previous surgery, and number of treated joints to be predictive for a shorter duration of effect of RF facet denervation $[28 \bullet$.

Whereas a diagnostic block is recommended to confirm the facet joint involvement, there is no consensus on the choice between intra-articular and ramus medialis injection, number of blocks to be performed, and cut-off value for judging the block to be positive. A comparison of the treatment outcome in patients reporting 50\%-79\% pain relief and those experiencing more than $80 \%$ pain relief for the duration of action of the local anesthetic showed no significant difference $[30 \bullet \bullet]$.

The accuracy of facet blocks also depends on the way the diagnostic block is performed [31•]. In the seven controlled studies on the efficacy of RF facet denervation there is one negative study [9] and one equivocal study [10]. In both of these studies, intra-articular injection of local anesthetic was used as diagnostic block instead of the block of the ramus medialis of the ramus dorsalis, the application of the local anesthetic on the nerve innervating the facet joint. Moreover, the interpretation of the diagnostic block used in the negative study is highly controversial as outlined above. Based on the evaluation of these studies, intra-articular injection of local anesthetic no longer can be recommended as a diagnostic for prediction of response to RF treatment.

Facet blocks, as with all diagnostic spinal injections, lack accuracy [32]. Reports of false-positive rates range between $20 \%$ and $40 \%$ [33-35]. These findings, and the observation that in studies where patients were selected by means of comparative blocks the number needed to treat is the lowest, led to the proposal for use of controlled or confirmative blocks [36-38].

However, there is controversy over the added value of multiplying the examinations before offering definite treatment to chronic pain patients. A well-conducted RCT investigated costs and outcomes of RF treatment using three different medial branch blocks treatment paradigms: 1) RF denervation without the use of a screening block; 2) RF denervation if the patient obtains significant relief after a single diagnostic block; and 3) RF denervation only if an appropriate patient has a positive response to two confirmatory blocks [39••]. By 3 months after RF treatment, the proportion of successful outcomes for each individual group cohort was highest in 
the group where patients received RF treatment without prior block $(33 \%)$ compared to $16 \%$ in the group of patients who had one diagnostic block and $22 \%$ in the group of patients who had comparative blocks. Based on the reimbursement scales applicable in the United States at the time of the study, the most cost-effective treatment was performed without prior diagnostic block. However, the success rates were reversed from the overall success rates when only those patients who received RF treatment were evaluated. In the group without diagnostic block, $33 \%$ of the patients had a successful outcome. This was $39 \%$ in the group with a single block and $64 \%$ in the double-block group. These findings confirm earlier observations that treatment outcome is better when the patients have been carefully selected [40, 41].

However, this does not mean that controlled blocks can be recommended as standard procedure. Indeed, with each additional diagnostic block, the number of false-positive blocks is reduced, but the number of false-negative blocks increases, which means that the risk of withholding efficacious treatment from patients is also increased.

Besides the balance of the burden of multiple interventions related to extra visits and interventions associated with controlled diagnostic blocks, the potential benefit also should be considered. In the mentioned controlled study [39•], a $25 \%$ increase in successful outcome is obtained with two diagnostic blocks, but this requires $100 \%$ more diagnostic interventions. Does the small gain in success justify the extra burden for the patient, the higher costs, and possible side effects of an additional treatment session? Moreover, only minor and transient side effects are reported in the literature after RF facet denervation [26].

The main objective of performing a diagnostic block is confirming the involvement of the facet joint and the level as diagnosed by clinical examination. However, there is a need for standardization. Based on the information from the literature, we suggest these measures:

- One block of the ramus medialis of the ramus dorsalis, no intra-articular injection;

- Three injection needles, placed at three adjacent levels under fluoroscopic control;

- A limited amount (maximum $0.7 \mathrm{~mL}$ ) of local anesthetic without corticosteroids per level;

- Evaluation of the change in pain intensity and functionality during the duration of action of the local anesthetic; and

- A VAS or numeric rating scale for assessment of the pain intensity, with a nurse assisting the patient in this assessment.

\section{Conclusions}

RF treatment of the lumbar ramus medialis of the ramus dorsalis (medial branch) has documented efficacy for the treatment of spine-related pain. The procedure can be repeated when symptoms return. The diagnosis can be made by a combination of clinical examination, medical imaging, and a diagnostic block. The low incidence of side effects and complications of the RF procedure justifies the use of only one diagnostic block as opposed to putting an extra burden on the patient and the health care system to perform a second controlled block.

Disclosures No potential conflicts of interest relevant to this article were reported.

Open Access This article is distributed under the terms of the Creative Commons Attribution Noncommercial License which permits any noncommercial use, distribution, and reproduction in any medium, provided the original author(s) and source are credited.

\section{References}

Papers of particular interest, published recently, have been highlighted as:

- Of importance

•- Of major importance

1. Glover JR. Arthrography of the joints of the lumbar vertebral arches. Orthop Clin North Am. 1977;8:37-42.

2. Cohen SP, Raja SN. Pathogenesis, diagnosis, and treatment of lumbar zygapophysial (facet) joint pain. Anesthesiology. 2007;106:591-614.

3. Schwarzer AC, Wang SC, Bogduk N, et al. Prevalence and clinical features of lumbar zygapophysial joint pain: a study in an Australian population with chronic low back pain. Ann Rheum Dis. 1995;54:100-6.

4. •-van Kleef M, Vanelderen P, Cohen SP, et al. 12. Pain Originating from the Lumbar Facet Joints. Pain Pract. 2010. This is the most recent review article on interventional pain management, focussing on anatomy, patient selection and diagnostic process. The evidence rating is a system that considers the potential burden and benefit of the treatment.

5. McDonald M, Cooper R, Wang MY. Use of computed tomography-single-photon emission computed tomography fusion for diagnosing painful facet arthropathy. Technical note. Neurosurg Focus. 2007;22:E2.

6. Wilde VE, Ford JJ, McMeeken JM. Indicators of lumbar zygapophyseal joint pain: survey of an expert panel with the Delphi technique. Phys Ther. 2007;87:1348-61.

7. Gallagher J, Vadi PLP, Wesley JR. Radiofrequency facet joint denervation in the treatment of low back pain-a prospective controlled double-blind study in assess to efficacy. Pain Clinic. 1994;7:193-8.

8. van Kleef M, Barendse GA, Kessels F, et al. Randomized trial of radiofrequency lumbar facet denervation for chronic low back pain. Spine. 1999;24:1937-42. 
9. Leclaire R, Fortin L, Lambert R, et al. Radiofrequency facet joint denervation in the treatment of low back pain: a placebocontrolled clinical trial to assess efficacy. Spine. 2001;26:14116. discussion 1417.

10. van Wijk RM, Geurts JW, Wynne HJ, et al. Radiofrequency denervation of lumbar facet joints in the treatment of chronic low back pain: a randomized, double-blind, sham lesion-controlled trial. Clin J Pain. 2005;21:335-44.

11. Nath S, Nath CA, Pettersson K. Percutaneous lumbar zygapophysial (Facet) joint neurotomy using radiofrequency current, in the management of chronic low back pain: a randomized double-blind trial. Spine. 2008;33:1291-7. discussion 1298.

12. Tekin I, Mirzai H, Ok G, et al. A comparison of conventional and pulsed radiofrequency denervation in the treatment of chronic facet joint pain. Clin J Pain. 2007;23:524-9.

13. Kroll HR, Kim D, Danic MJ, et al. A randomized, double-blind, prospective study comparing the efficacy of continuous versus pulsed radiofrequency in the treatment of lumbar facet syndrome. J Clin Anesth. 2008;20:534-7.

14. Geurts JW, van Wijk RM, Stolker RJ, Groen GJ. Efficacy of radiofrequency procedures for the treatment of spinal pain: a systematic review of randomized clinical trials. Reg Anesth Pain Med. 2001;26:394-400.

15. Boswell MV, Colson JD, Sehgal N, et al. A systematic review of therapeutic facet joint interventions in chronic spinal pain. Pain Physician. 2007;10:229-53.

16. Hooten WM, Martin DP, Huntoon MA. Radiofrequency neurotomy for low back pain: evidence-based procedural guidelines. Pain Med. 2005;6:129-38.

17. Niemisto L, Kalso E, Malmivaara A, et al. Radiofrequency denervation for neck and back pain: a systematic review within the framework of the cochrane collaboration back review group. Spine. 2003;28:1877-88.

18. Slipman CW, Bhat AL, Gilchrist RV, et al. A critical review of the evidence for the use of zygapophysial injections and radiofrequency denervation in the treatment of low back pain. Spine J. 2003;3:310-6.

19. Manchikanti L, Singh V, Vilims BD, et al. Medial branch neurotomy in management of chronic spinal pain: systematic review of the evidence. Pain Physician. 2002;5:405-18.

20. Boswell MV, Trescot AM, Datta $\mathrm{S}$, et al. Interventional techniques: evidence-based practice guidelines in the management of chronic spinal pain. Pain Physician. 2007;10:7-111.

21. van Tulder MW, Koes B, Seitsalo S, Malmivaara A. Outcome of invasive treatment modalities on back pain and sciatica: an evidence-based review. Eur Spine J. 2006;15 Suppl 1:S82-92.

22. - Chou R, Atlas SJ, Stanos SP, Rosenquist RW. Nonsurgical interventional therapies for low back pain: a review of the evidence for an American Pain Society clinical practice guideline. Spine (Phila Pa 1976). 2009;34:1078-1093. This review article is mainly based on previous assessments.

23. Moher D, Cook DJ, Eastwood S, et al. Improving the quality of reports of meta-analyses of randomised controlled trials: the QUOROM statement. Quality of Reporting of Meta-analyses. Lancet. 1999;354:1896-900.

24. Moher D, Liberati A, Tetzlaff J, Altman DG. Preferred reporting items for systematic reviews and meta-analyses: the PRISMA statement. PLoS Med. 2009;6:e1000097.

25. • Van Zundert J, Vanelderen P, Kessels AG. Re: Chou R, Atlas SJ, Stanos SP, et al. Nonsurgical interventional therapies for low back pain: a review of the evidence for an American Pain Society clinical practice guideline. Spine (Phila Pa 1976) 2009;34: 107893. Spine (Phila Pa 1976). 2010;35:841; author reply 841-842. This is a letter to the editor in response to the methodology of the review article.
26. Kornick C, Kramarich SS, Lamer TJ, Todd Sitzman B. Complications of lumbar facet radiofrequency denervation. Spine. 2004;29:1352-4.

27. Rambaransingh B, Stanford G, Burnham R. The effect of repeated zygapophysial joint radiofrequency neurotomy on pain, disability, and improvement duration. Pain Med. 2010;11:1343-7.

28. - Streitberger K, Muller T, Eichenberger U, et al. Factors determining the success of radiofrequency denervation in lumbar facet joint pain: a prospective study. Eur Spine J. 2011. This is a prospective study indicating that depression may shorten the duration of action of radiofrequency treatment of the lumbar ramus medialis of the ramus dorsalis.

29. Cohen SP, Hurley RW, Christo PJ, et al. Clinical predictors of success and failure for lumbar facet radiofrequency denervation. Clin J Pain. 2007;23:45-52.

30. • Cohen SP, Stojanovic MP, Crooks M, et al. Lumbar zygapophysial (facet) joint radiofrequency denervation success as a function of pain relief during diagnostic medial branch blocks: a multicenter analysis. Spine J. 2008;8:498-504. This study indicates that there is no difference in success rate when patients are included who experience over $50 \%$ and less than $79 \%$ pain relief after the diagnostic block compared with the patients who experience over $80 \%$ pain relief.

31. • Van Zundert J, Mekhail N, Vanelderen P, van Kleef M. Diagnostic Medial Branch Blocks before Lumbar Radiofrequency Zygapophysial (Facet) Joint Denervation: Benefit or Burden? Anesthesiology. 2010. This letter to the editor highlights the importance of falsepositive diagnostic blocks and false-negative diagnostic blocks, resulting in a balanced proposal for the diagnostic blocks.

32. Cohen SP, Hurley RW. The ability of diagnostic spinal injections to predict surgical outcomes. Anesth Analg. 2007;105:1756-75. table of contents.

33. Schwarzer AC, Aprill CN, Derby R, et al. The false-positive rate of uncontrolled diagnostic blocks of the lumbar zygapophysial joints. Pain. 1994;58:195-200.

34. Revel M, Poiraudeau S, Auleley GR, et al. Capacity of the clinical picture to characterize low back pain relieved by facet joint anesthesia. Proposed criteria to identify patients with painful facet joints. Spine. 1998;23:1972-6. discussion 1977.

35. Manchikanti L, Pampati V, Fellows B, Bakhit CE. The diagnostic validity and therapeutic value of lumbar facet joint nerve blocks with or without adjuvant agents. Curr Rev Pain. 2000;4:337-44.

36. Bogduk N. International Spinal Injection Society guidelines for the performance of spinal injection procedures. Part 1: Zygapophysial joint blocks. Clin J Pain. 1997;13:285-302.

37. Sehgal N, Dunbar EE, Shah RV, Colson J. Systematic review of diagnostic utility of facet (zygapophysial) joint injections in chronic spinal pain: an update. Pain Physician. 2007;10:213-28.

38. Bogduk N. Evidence-informed management of chronic low back pain with facet injections and radiofrequency neurotomy. Spine J. 2008;8:56-64.

39. • Cohen SP, Williams KA, Kurihara C, et al. Multicenter, randomized, comparative cost-effectiveness study comparing 0 , 1 , and 2 diagnostic medial branch (facet joint nerve) block treatment paradigms before lumbar facet radiofrequency denervation. Anesthesiology. 2010;113:395-405. This is the first randomized controlled trial evaluating the role of one or more diagnostic blocks in function of not only treatment outcome but also cost-effectiveness.

40. van Boxem K, van Eerd M, Brinkhuize T, et al. Radiofrequency and pulsed radiofrequency treatment of chronic pain syndromes: the available evidence. Pain Pract. 2008;8:385-93.

41. Van Zundert J, Van Boxem K, Joosten EA, Kessels A. Clinical trials in interventional pain management: optimizing chances for success? Pain. 2010;151:571-4. 